\title{
Time-Domain Spectral IP and Its Applications in the Southern Chinkuashih Area, Northern Taiwan
}

\author{
Chow-Son Chen ${ }^{1, *}$ and Shuhjong Tsao ${ }^{2}$ \\ (Manuscript received 15 May 2001, in final form 24 September 2001)
}

\begin{abstract}
The IP measurement has a low background value above which IP data can be called anomalous, yielding a more definitive interpretation than other geophysical methods. For resolving IP sources, broad band IP data should be collected. The most cost effective way to obtain enough spectral IP (SIP) information routinely is by time-domain SIP measurement. Although the Cole-Cole parameters (chargeability $M$, time const $T$ and exponent $c$ ) have been found to be very useful in resolving SIP sources in a frequency-domain, these parameters can also be determined through computer matching of the time-domain SIP data by the best fit in a family of pre-calculated ColeCole curves.

Time-domain SIP has first been applied to the southern Chinkushih area, northern Taiwan, for the resolution of SIP sources. Based on the time domain SIP analysis, possible concealed porphyry gold/copper deposits, or breccia pipes in the margin of the Wutanshan intrusion were located.
\end{abstract}

(Key words: Time-domain SIP, Source discrimination, Chinkuashih Area)

\section{INTRODUCTION}

Induced polarization (IP) is a current-stimulated electrical phenomenon observed as delayed voltage response in the earth materials (Sumner 1976). The primary advantage of the IP method is its capability under favorable conditions to detect the presence of even very small amounts of metallic minerals, such as disseminated mineralization, where other geophysical exploration methods are much less effective in this regard.

As a first step towards understanding the IP method, a tank model experiment of IP across an ore body of different grain sizes has been conducted. Figure 1 shows the tank model set up for IP modeling. The model tank consists of a PVC tank $(60 \mathrm{~cm}$ by $50 \mathrm{~cm}$ by $45 \mathrm{~cm})$. The tank was filled with water and sponge whose electrical conductivity could be adjusted by adding

\footnotetext{
${ }^{1}$ Institute of Geophysics, National Central University, Chung-Li, Taiwan, ROC

${ }^{2}$ Central Geological Survey, Taiwan, ROC

${ }^{*}$ Corresponding author address: Prof. Chow-Son Chen, Institute of Geophysics, National Central University, Chung-Li, Taiwan, ROC; E-mail: chusen@sal.gep.ncu.edu.tw
} 


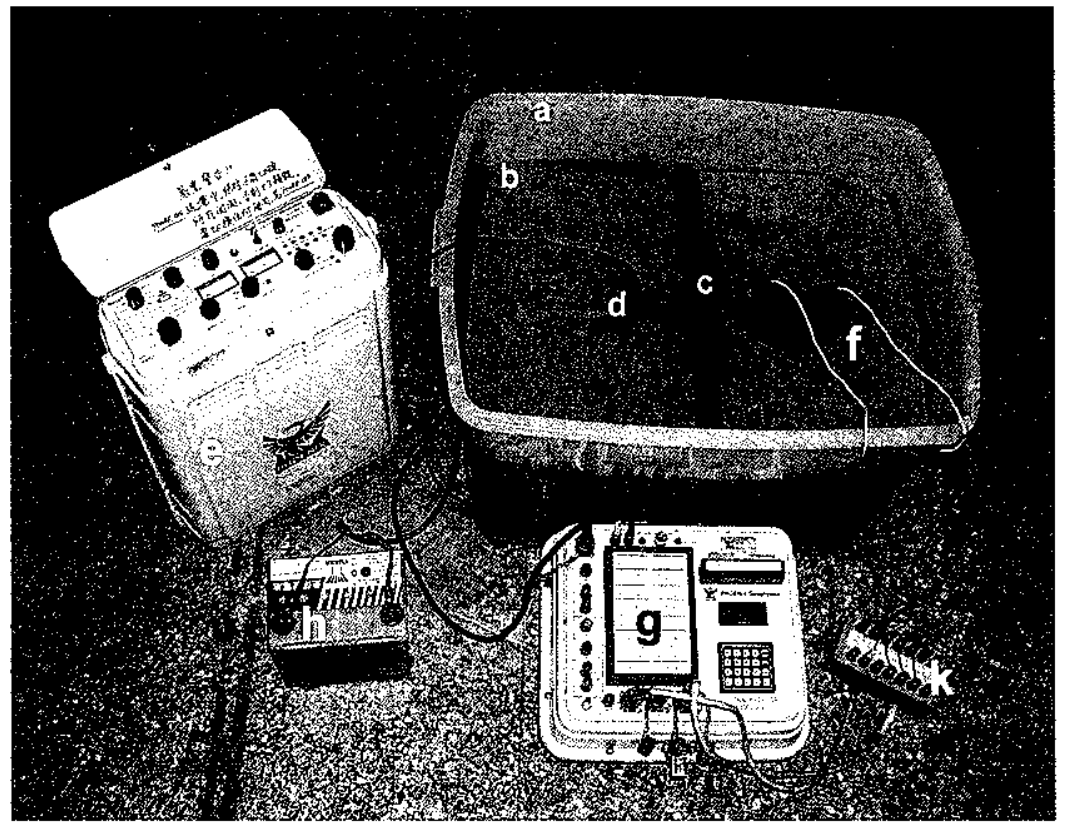

Fig. 1. Model tank set-up for SIP modeling. The model tank consists of a PVC tank (a). The tank was filled with water and sponge (b). The ore sheet was prepared from a stainless steel net of different mesh sizes (c). The measurements were carried out with the dipole-dipole array system. The transmitting dipole (d) was energized using Phoenix T3 by $4.5 \mathrm{~V}$ (e). The receiving dipole with non-polarized $\mathrm{PbCl}_{2}$ pots (f) was measured with Phoenix V4 receiver ( $g$ ). $h=12 v$ battery; $k=$ adaptor.

electrolyte $(\mathrm{NaCl})$ solution. The water and sponge simulates the host medium and an anomalous ore sheet was prepared from a conducting net (made of stainless steel) of different mesh sizes. In the present case, we used 16 meshes $/ \mathrm{mm}^{2}$ and $1 \mathrm{mesh} / \mathrm{mm}^{2}$, all of them of same weight $40 \mathrm{~g}$.

The measurements were carried out with the dipole-dipole array system. The transmitting dipole (dipole length $5 \mathrm{~cm}$ ) was energized using Phoenix T3, and the voltage across the receiving dipole (non-polarized $\mathrm{PbCl}_{2}$ dipole with dipole length $10 \mathrm{~cm}$ ) was measured with the help of a Phoenix V4. Both transmitter and receiver are in situ IP equipment. The transmitting voltage should be decreased (by say $4.5 \mathrm{~V}$ ) in tank modeling.

Results (Table 1) show that total chargeabilities (IP responses) are found to be more sensitive to the variation in the mesh size than the receiving voltages (resistivity responses). Moreover, the rate of decay of induced polarization voltages after the interruption of the inducing current (Fig. 2) was strongly dependent on the mesh sizes, i.e., the mean particle size of the metallic grains. A consequence of this observation is that it is feasible, through a measurement of the rate of decay of IP signals in the earth, to obtain information concerning the mean particle size of the IP source material. 
Table 1. Tank model experiments of conductors of different mesh sizes.

\begin{tabular}{|c|c|c|}
\hline Model (stainless steel) & Primary voltage $(\mathrm{mV})$ & Total chargeability \% \\
\hline 16 meshe $/ \mathrm{mm}^{2}$ & 6.439 & 10.949 \\
\hline 1 mesh $/ \mathrm{mm}^{2}$ & 6.352 & 6.176 \\
\hline Background & 6.522 & -6.131 \\
\hline
\end{tabular}

Actually, in the IP method, the presence of an indication in itself is sufficient to define an anomaly, rather than a difference in measurement level. That is to say, the IP phenomenon usually has a low background or threshold value above which measurements can be simply called anomalous. In contrast, non-IP geophysical exploration methods, such as gravitation, magnetic, seismic, and even resistivity methods, measure effects due to differences in the physical properties of rocks. Anomalous differences in their apparent values, however, are often small compared with the normal variation of the fundamental property. Thus, there is an advantage to the IP method in that it yields a more definitive interpretation.

The purpose of this paper is to apply the broad band IP technique to the southern Chinkushih area, northern Taiwan, for the resolution of IP sources. Based on the time domain IP analysis, possible concealed mineral deposits in the margin of the Wutanshan intrusion were discovered.

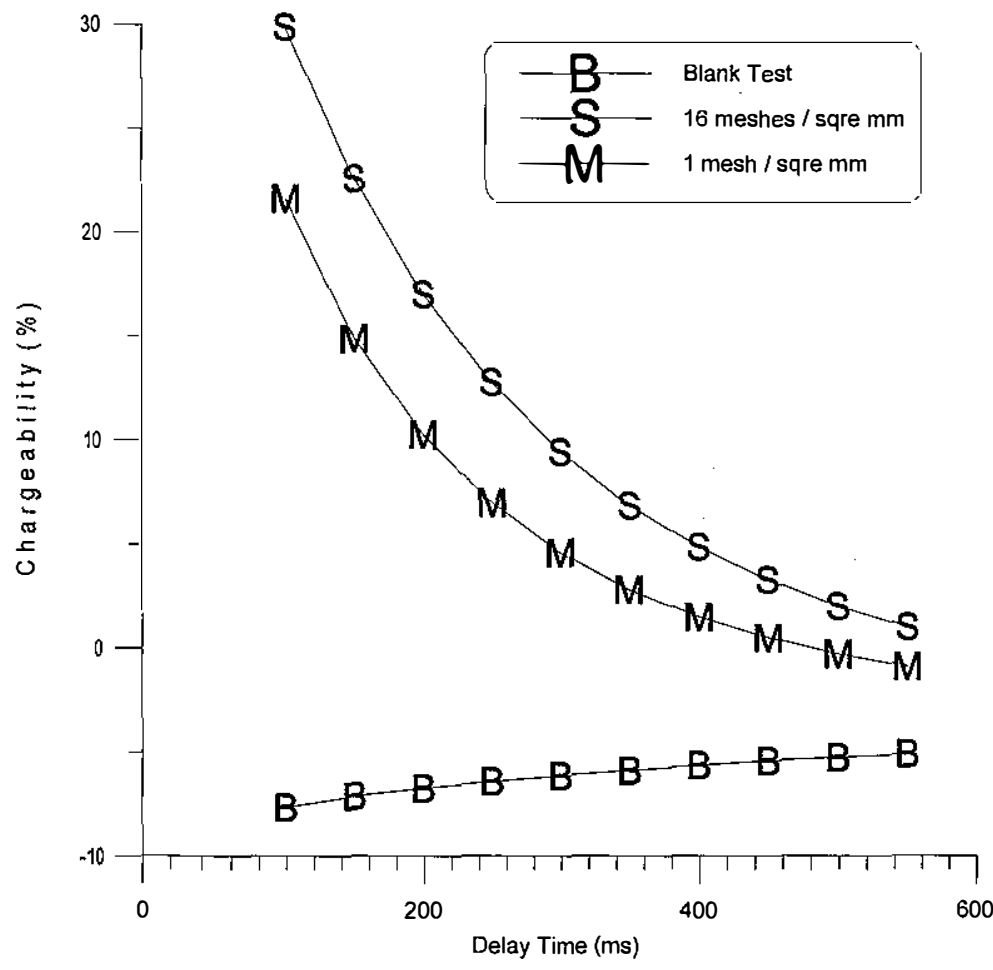

Fig. 2. The rate of decay of IP voltages after the interruption of the inducing current was strongly dependent on the mesh sizes; the finer the mesh sizes, the stronger the IP response. 


\section{THEORITICAL BASIS OF SPCTRAL IP}

A common mathematical model for representation of the broad band IP response of the earth was proposed by Pelton et al. (1978). He proposed that the Cole-Cole frequency domain impedance model be adopted (Fig. 3). This model suggests that the complex transfer impedance of a four-electrode system, which includes a dispersive, or polarizable earth segment, can be expressed as

$$
Z(w)=R\left(1-M\left(1-1 /\left(1+(i w T)^{c}\right)\right)\right),
$$

where $Z(w)$ is the complex impedance in ohms, $R$ is the dc resistance in ohms, $M$ is the chargeability amplitude (dimensionless), $\mathrm{T}$ is the time constant in seconds, $\mathrm{w}$ is the angular frequency in $\mathrm{Hz}, \mathrm{c}$ is the exponent (dimensionless), and $\mathrm{i}$ is the square root of $(-1)$.

Pelton et al. (1978) working in the frequency domain, coined the term "spectral IP" (SIP) to denote the transmission of waveforms of multiple frequencies in the earth, and the measurement of the variation of its complex impedance across the frequency spectrum employed. It provides a useful approach, which may be routinely applied to the characterization and differentiation of IP sources.

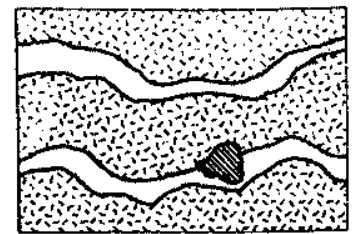

MINERALIZED ROCK. (a)

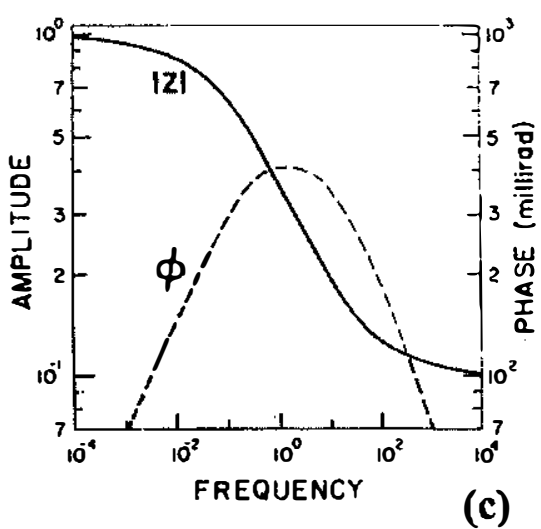

(b)

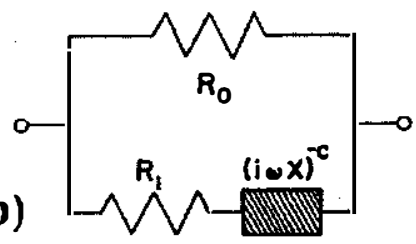

EQUIVALENT CIRCUIT

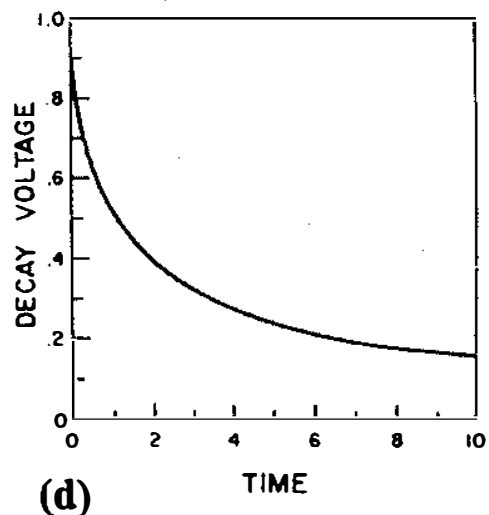

(d)

Fig. 3. (a) A small section of a mineralized rock which has both blocked and unblocked pore passages. (b) An equivalent circuit for the mineralized rock. (c) Typical frequency domain response for the equivalent circuit. (d) Time domain response corresponding to the frequency domain response plotted in (c). Note that (c) and (d) are Fourier transform pairs. (After Pelton et al. 1978) 


\subsection{Cole-Cole Parameters}

The three Cole-Cole IP parameters, M, T, and C, each has a physical significance relative to the IP source material. The chargeability parameter (M) is the residual voltage that would be seen immediately after the shut-off of an infinitely long transmitted current pulse, divided by the observed voltage just before the shut-off (Fig. 3d). The value of $\mathrm{M}$ ranges from 0 to 1.0. The time constant (T) determines the rate of decay of the residual voltage (Fig. 3d) and increases with the average metallic grain size of the IP source. In practice, this parameter has been found to exhibit a very broad range, from $10^{-3}$ seconds to $10^{3}$ seconds. The exponent (c) controls the shape (curvature) of the decay curve (in log-log space), and physically relates to the particle size distribution in the IP source (Fig. 3c). Generally speaking, in practice, it is observed to range from about 0.1 (for very wide size distribution) to about 0.6 (for a very sharply peaked distribution), with most observed values lying in the range between 0.1 and 0 . 3.

\subsection{Time Domain SIP}

SIP measurement entails the sequential transmission of waveforms of different fundamental frequencies (Fig. 4a), spanning the desired frequency band, usually $10^{-2}$ to $10^{2} \mathrm{~Hz}$ or more. In the time domain, one bipolar, interrupted, square waveform, with duration of, say, 2 to $4 \mathrm{~s}$ on-off, is applied, and the transient decay voltage curve is measured and recorded over the current-off time period (Fig. 4b). The time domain SIP, which we employed in the tank modeling, has the advantage of a shorter measuring time, since each transient curve, by itself, contains information relating to IP effects over a frequency spectrum that typically spans up to three decades, e.g., $10^{-2}$ to $10^{2} \mathrm{~Hz}$. Besides, the lower frequencies used in the time domain ensure that there will be less noise from electromagnetic coupling with the earth. Electromagnetic effects may become particularly prominent when surveys are carried out using large electrode separations and/or in areas where resistivities are low. This noise interferes with the IP signal, degrading results. Therefore, time domain measurement is the most cost effective way to obtain enough spectral IP information routinely, from which the Cole-Cole parameters may be derived.

\subsection{Time Domain Cole-Cole Parameters}

A simpler and more direct approach is to generate a family of steady-state theoretical transient decay curves, for different values of $\mathrm{T}$ and $\mathrm{C}$, for a train of current pulses (Tombs 1981) for specific values of the current-on/off times. These curves maybe plotted in the form of log-amplitude versus log-time. This representation separates the dependence of the decay curve on the chargeability (amplitude) and allows us to deal with the curve shape itself.

The data for these Cole-Cole transient master curves are then stored in a computer lookup table. A computer program performs a search for the master curve whose shape best fits that of the observed transient data. This then determines the appropriate values of $\mathrm{T}$ and $\mathrm{C}$. The value of $\mathrm{M}$ is then also determined by the computer program, based on the amplitude of the observed transient voltages. The computer program usually indicates the ìgoodness of fitî or correlation 
(a)

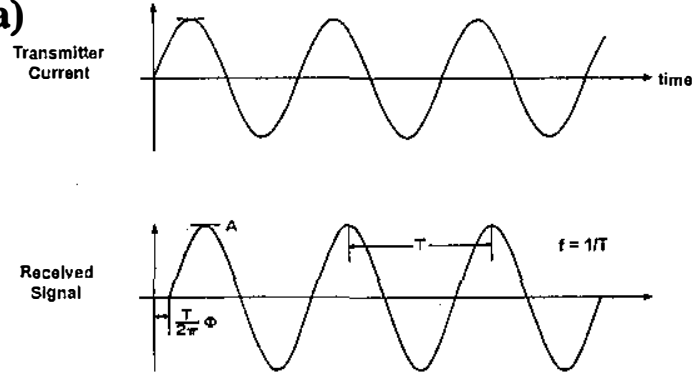

Fig. 4. Transmitted and received waveforms in (a) frequency

(b)

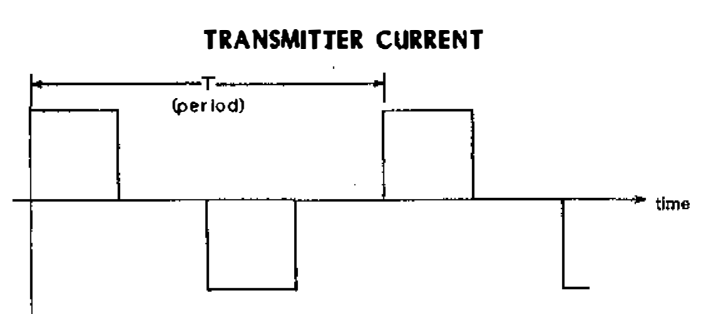
domain, and (b) timedomain.

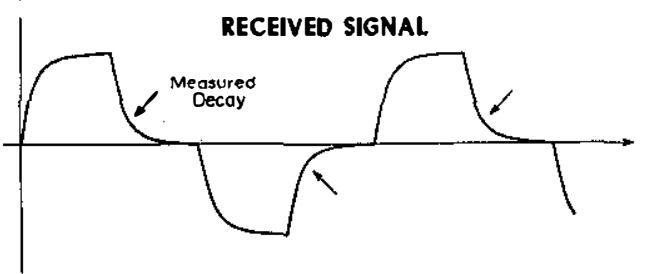

coefficient of the observed transient curve to the best fit curve selected from the family of theoretical curves. Reliance can only be placed on those parameters whose model represents a good fit, i.e., with a fit of 0.9 or better.

\section{APPLICATION OF TIME DOMAIN SIP}

\subsection{The Chinkuashih Deposits}

The Chinkuashih (CKS) deposits in the northern Taiwan produced 92 tons of gold,119101 tons of copper, and 183 tons of silver from about 20 million tons of ore from 1898 to 1987 (Tan 1991). Copper-gold mineralizations of the CKS area are associated with several latePliocene-Pleistocene dacites/andesite intrusions (Fig. 5). However, the ore deposits surrounding the CKS have not been adequately accounted for. An intrusive structure which is outlined by the Wutanshan dacite has been interpreted by gravity data (Tzou 1979) and then by magnetic survey (Tong and Chen 2000) which might suggest possible concealed gold deposits. National Central University (NCU) was asked to joint a geophysical survey using SIP method sponsored by the Central Geological Survey (CGS) over the most potential area, the Wutanshan intrusion (Fig. 5). 


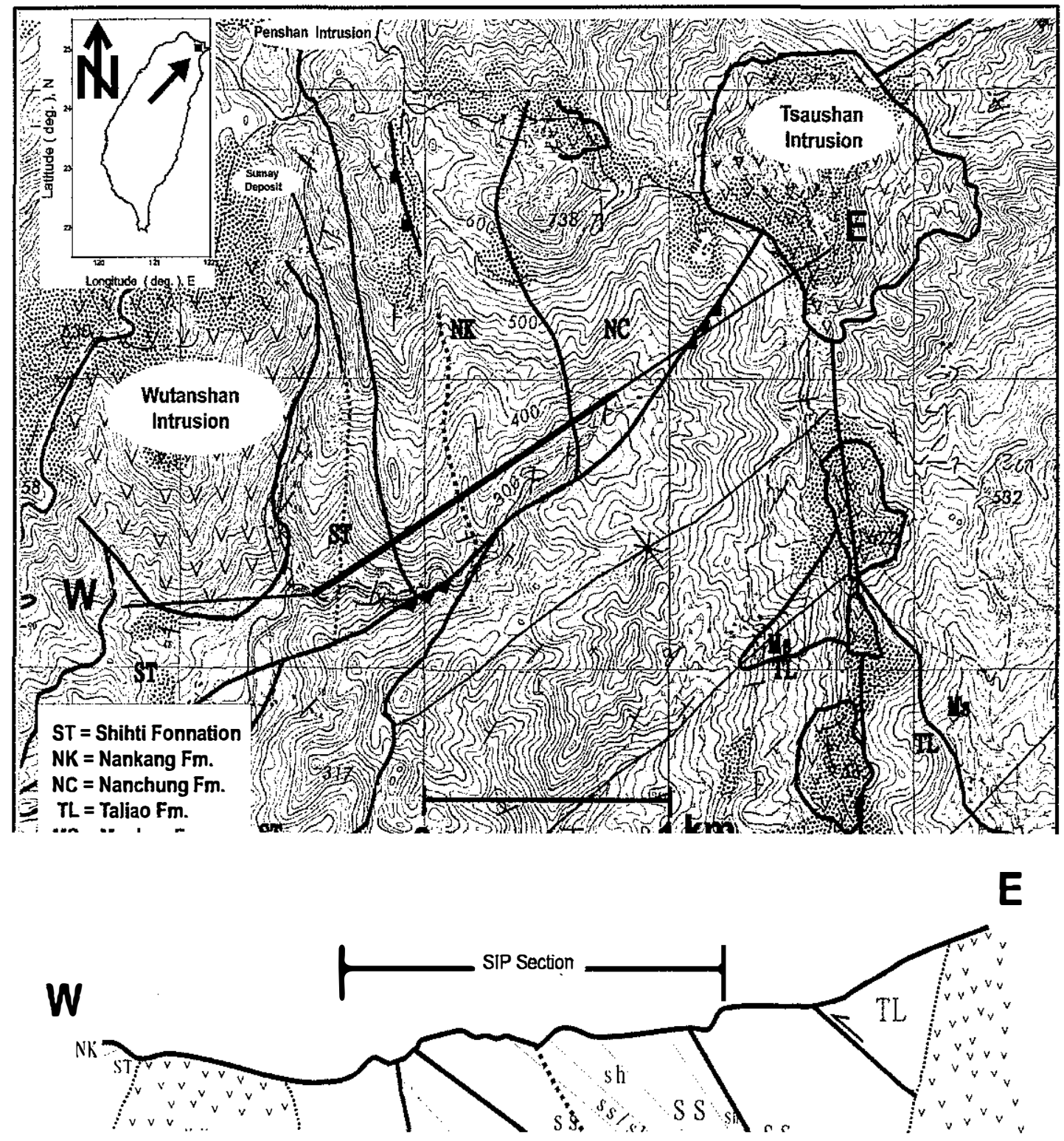

Fig. 5. Location of the SIP survey (bold line) of the study area and its associated geology. Copper-gold mineralizations of the CKS area are associated with several late-Pliocene-Pleistocene dacites/andesite intrusions, e.g., Wutanshan intrusion, Tsashan intrusion, and Penshan intrusion. 


\subsection{Time Domain SIP Survey}

The time domain SIP survey is quite the same with the traditional direct current resistivity survey. However, the electrodes used for time domain SIP survey require special consideration because the delayed voltage is much lower than the primary voltage. The current electrodes must be of low impedance in order that a modest voltage source of order 100-1000 v may drive 1 to $20 \mathrm{~A}$ of current. About 1 to 5 gallons of salt water $(\mathrm{NaCl})$ is applied prior to and after emplacing the electrodes. The salt solution effectively increases the area of the electrode, especially if the electrode is continuously used for several days after its emplacement. Several electrodes in parallel, placed $1 \mathrm{~m}$ to $2 \mathrm{~m}$ apart, will lower impedances in mountain area, as in the CKS deposits. Vertical iron stakes driven at least $0.3 \mathrm{~m}$ into the ground and watered, can at times make acceptable transmitting electrodes.

The potential electrodes, on the other hand, are not required to be of low impedance. Rather, they must be of low noise. Nonpolarizing $\mathrm{Pb}-\mathrm{P} 1 \mathrm{Cl}_{2}$ electrodes are employed. $\mathrm{Pb}-\mathrm{PlCl}_{2}$ electrodes trend to be more stable than traditional $\mathrm{Cu}-\mathrm{CuSO}_{4}$ electrodes.

About arrays in conducting SIP survey, either the dipole-dipole or pole-dipole array is used in order to minimize electromagnetic coupling. The pole-dipole array is especially suitable in rugged topography as in CKS area.

The time-domain transmitter (Phoenix T3) current employed the 2 seconds on/off waveform. The receiver employed was the Phoenix V4, which integrates and records over 10 time windows, on the transient decay curve (Fig. 6).

\subsection{SIP Results In The Southern CKS Area}

Figure 7 shows the results of the time domain SIP profile in the southern CKS area, employing a pole-dipole array, with dipole length $\mathrm{a}=20$ and $40 \mathrm{~m}$, and $\mathrm{n}$ ranging from 1 to 7 . The results are shown in the form of pseudosections of resistivity (Fig. 7b) and chargeability (Fig. 7c), as well as the geologic section (Fig. 7a) of the profile. It may be seen that there are four strong and distinct chargeability zones (10 times background value $2 \%$ ), lying at some depth 50 m below surface, i.e., under 200, 500, 1100, and $1300 \mathrm{~m}$, indicated by A, B, C, and D, respectively, on this traverse. Each of these IP anomalous zones is marked by major resistivity changes (Fig. 7b); the general resistivity anomaly levels lie in the range of 300-400 ohm-m, against a background resistivity of less than $100 \mathrm{ohm}-\mathrm{m}$. This correlation is not complete because the ore body (strong chargeability zones) is offset from the volcanic intrusive (high resistivity zones).

In order to resolve the IP sources, the time constant of each IP anomaly should be analyzed. Some of the typical chargeability-time records of this study are shown in Fig. 8. The chargeability time slices, $\mathbf{M}_{2}$ to $\mathrm{M}_{10}$ (with equal time window $50 \mathrm{~ms}$ after $20 \mathrm{~ms}$ delay of termination of the current pulse) are organized and shown in Fig. 9. Again it may be seen that the four strong and distinct IP indications A, B, C, and D, lying in the section of the line, diminished differently as time increased. This means that those 4 anomalies each have different time constants.

Figure 10 shows the Cole-Cole parameters, determined by using a best fit the master curve as stated in section 2.3, in pseudosection form, including the time constant $\mathrm{T}$ and expo- 
(a)

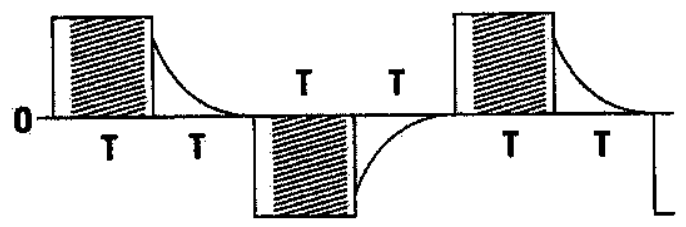

(b)

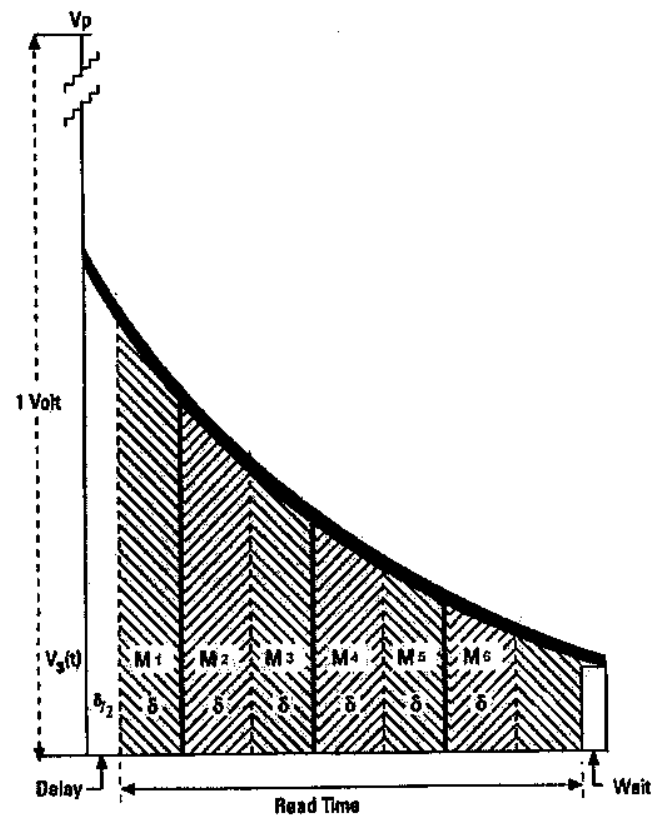

Fig. 6. Time domain SIP waveform. After the chargeability integration program is initiated, the values of the primary voltage $\mathrm{Vp}$ (a) and the chargeability $\mathbf{M}$ (b) are averaged and updated after each current pulse pair. The $\mathbf{M}$ values are in $\mathrm{mv} / \mathrm{v}$, i.e., they are normalized for $\mathrm{Vp}$, slice width, number of pulses and curve shape. The receiver also store the time slices (from $M_{1}$ to $M_{10}$ ) with equal time window $50 \mathrm{~ms}$ after $20 \mathrm{~ms}$ delay of termination of the current pulse in this study.

nent c. The T values (Fig. 10b) in the same vicinity of the anomaly zones are characterized by relatively long $\mathrm{T}, 10^{-0.5}$ to $10^{0.5} \mathrm{~s}$, against a background $\mathrm{T}$ of $10^{-2}$ to $10^{-1} \mathrm{~s}$. In the absence of drill hole confirmation at the present stage, however, based on SIP theory stated above, it should be noted that the long-time constant (greater than $10^{\circ} \mathrm{s}$ ) zone is typical of coarse-grained, wellinterconnected sulphides, whereas the short time constant zone (less than $10^{\circ} \mathrm{s}$ ) is of non-metallic or gold deposits with fine size grains. 
(a)

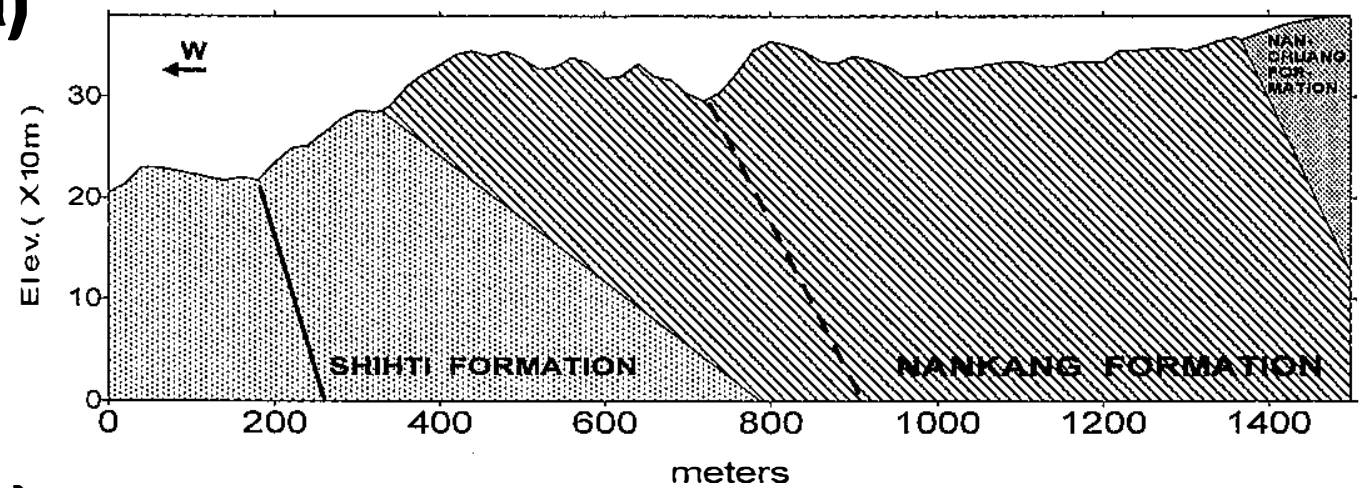

\section{(b) Res.}

meters

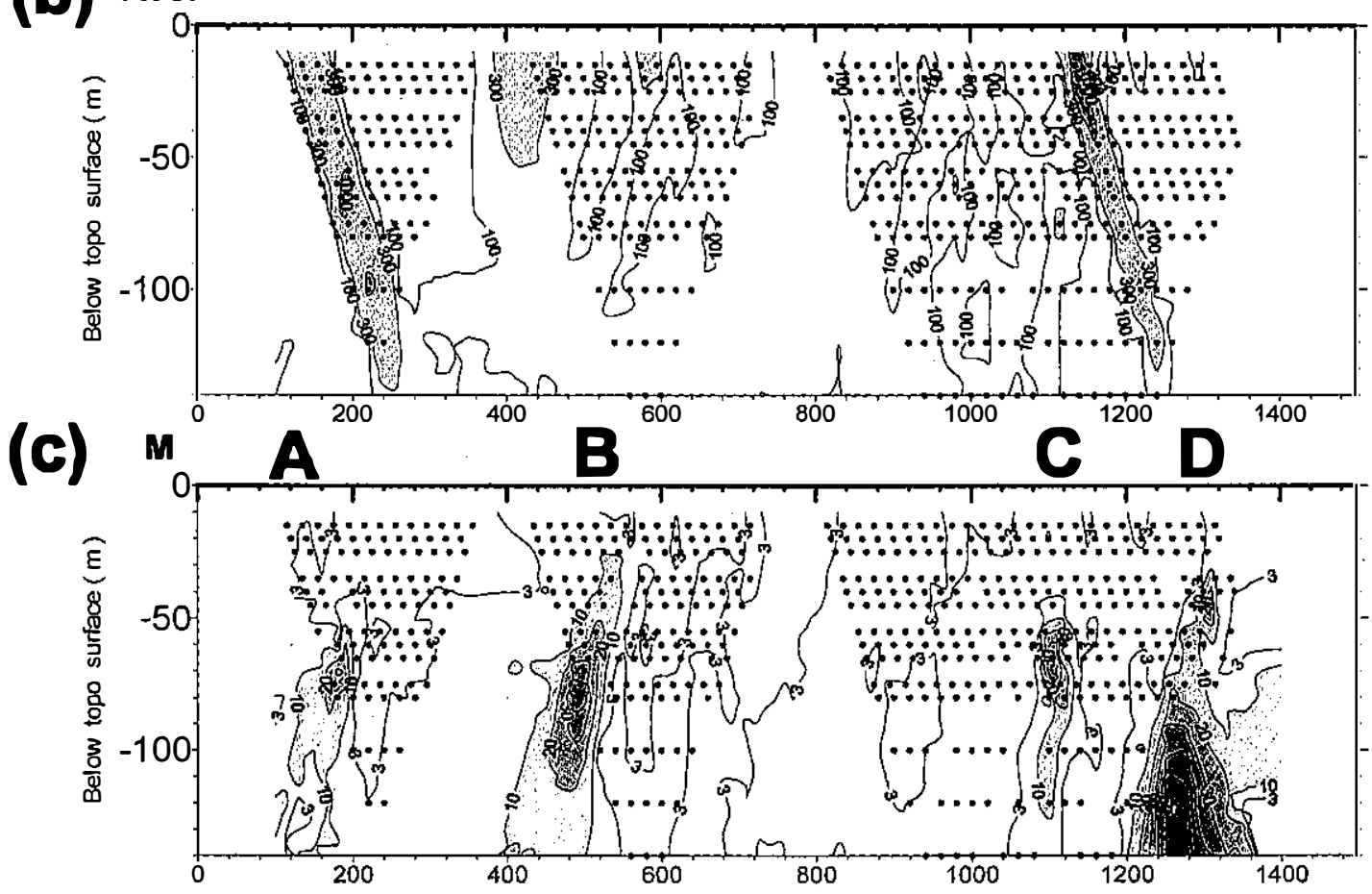

Fig. 7. (a) The geologic section of the studying profile in the southern CKS area. (b) The pseudosection of resistivity in ohm-m. (c) The pseudosection of chargeability in \%. Data (solid circles) under about $400 \mathrm{~m}$ and about 800 $\mathrm{m}$ were unrecorded due to rugged topography, therefore, avoiding topographic effect in interpretations. Note that the four strong and distinct IP indications $\mathrm{A}, \mathrm{B}, \mathrm{C}$, and $\mathrm{D}$, lying in the section of the line. 


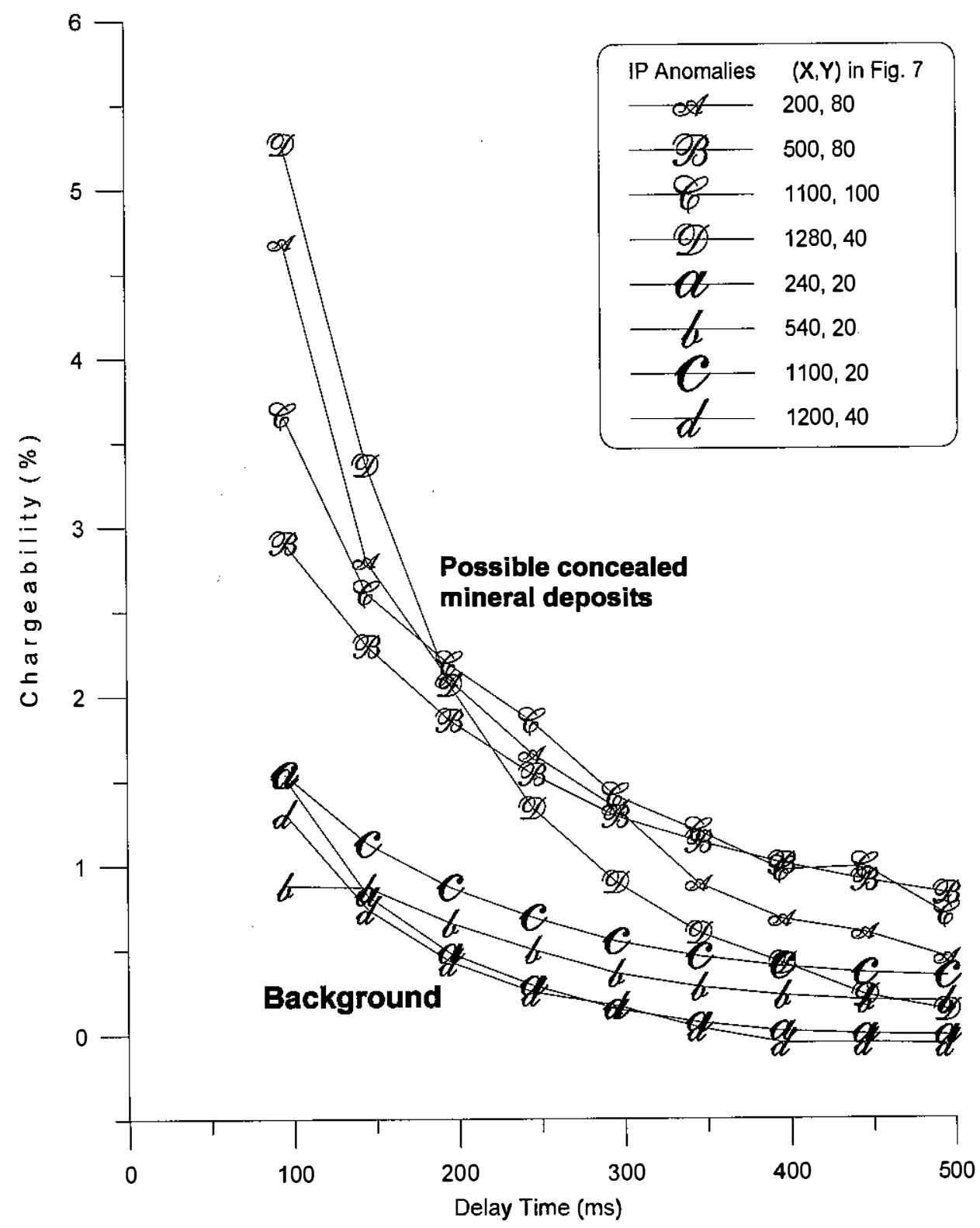

Fig. 8. Some typical time domain SIP curves in the southern CKS area. The location of each data set is shown in Fig. 7c.

The computed $\mathrm{c}$ values (Fig. 10c) are generally 0.5 to 0.6 within the IP anomaly portion. However, as $\mathrm{c}$ value increased too much to near 1.0, the IP anomaly was most probably caused by electromagnetic coupling (Pelton et al. 1978). Therefore, the eastern side of $\mathrm{D}$ anomaly, its c value higher than 0.7 , is suspected to be caused by nonmetallic polarization. 

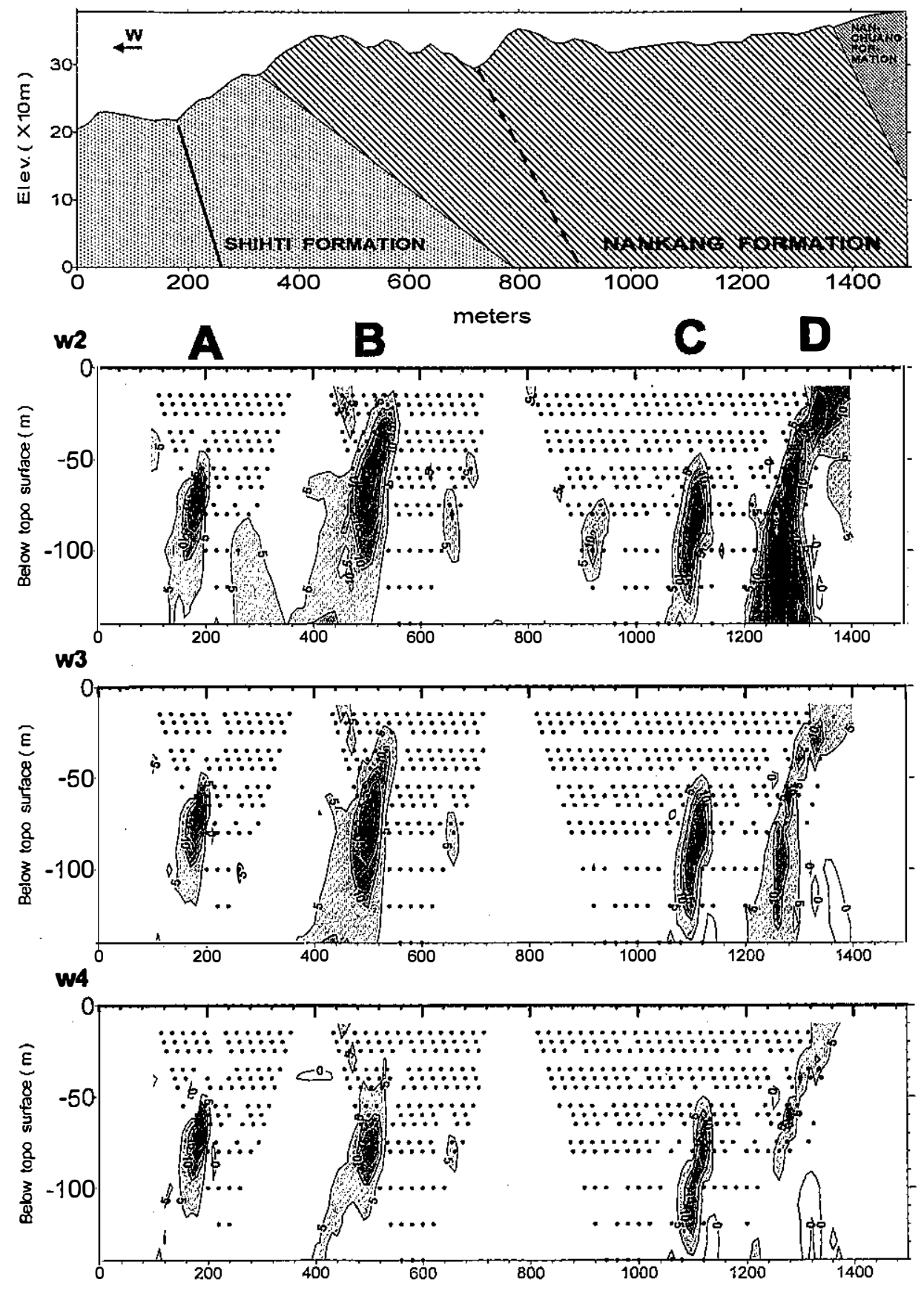

Fig. 9. The chargeability time slices, from $M_{2}$ to $M_{10}$ of the study profile. Note that the four strong and distinct IP indications A, B, C, and D, lying in the section of the line. The IP anomaly diminished differently as time increase; this means that the anomaly have different time constants. 

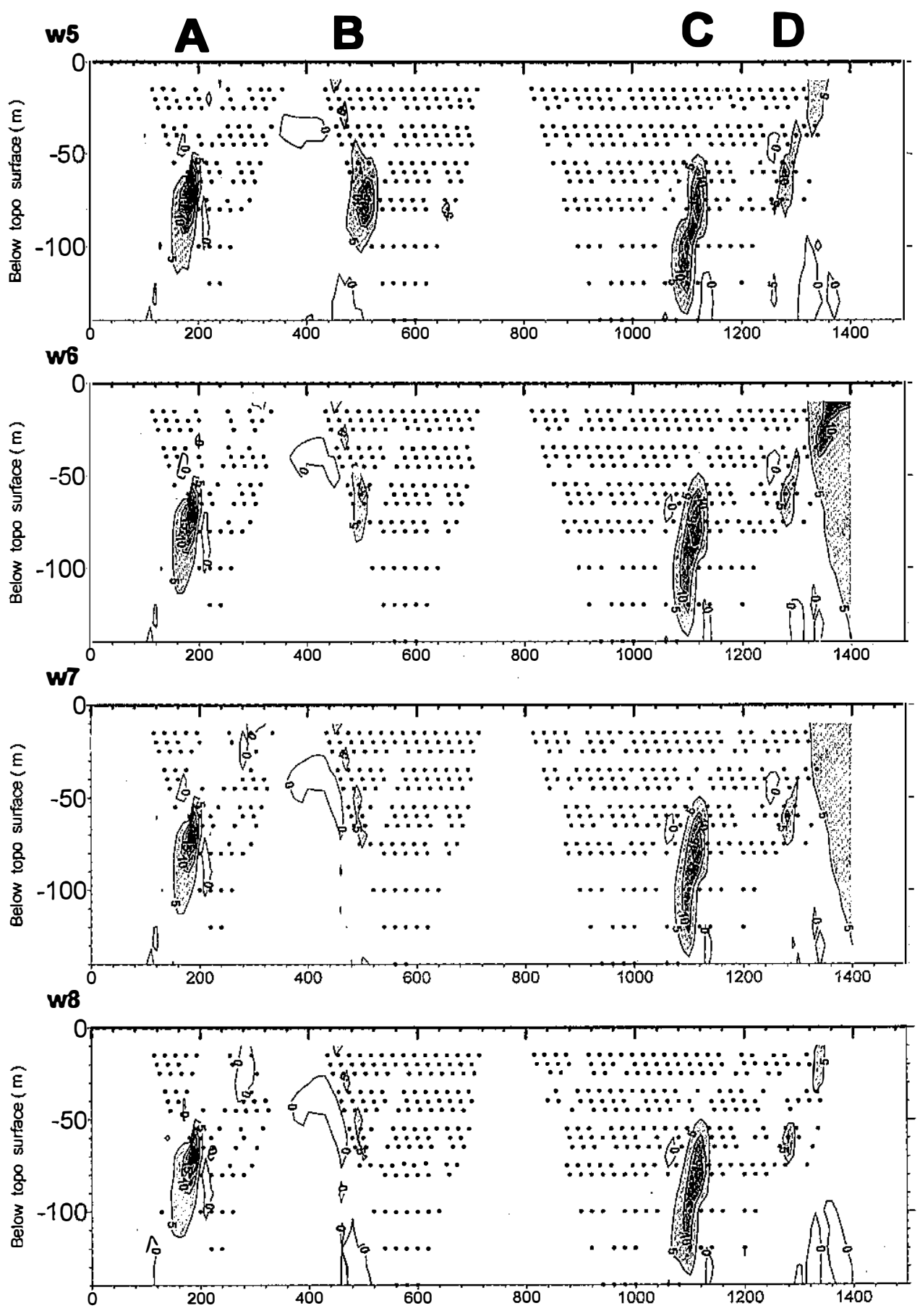

(Fig. 9. continued) 
(a)

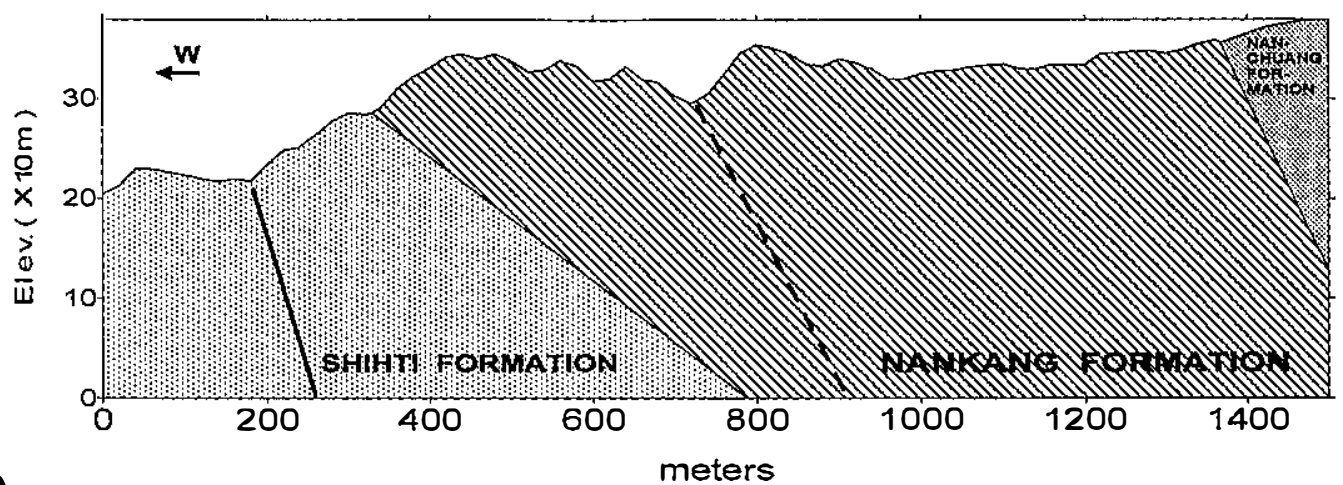

(b) $\log (\mathrm{T})$

meters

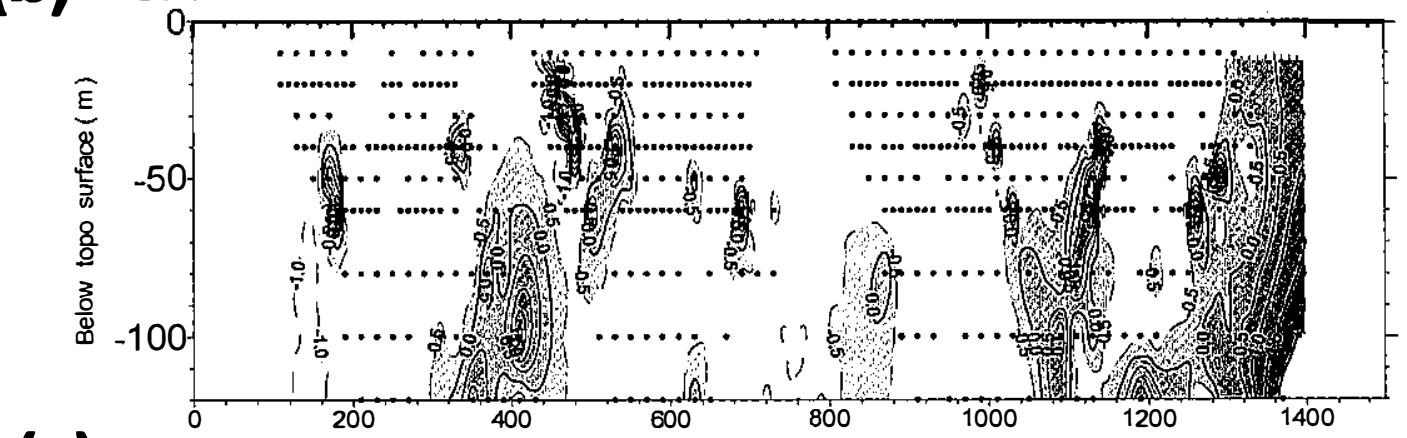

(c)

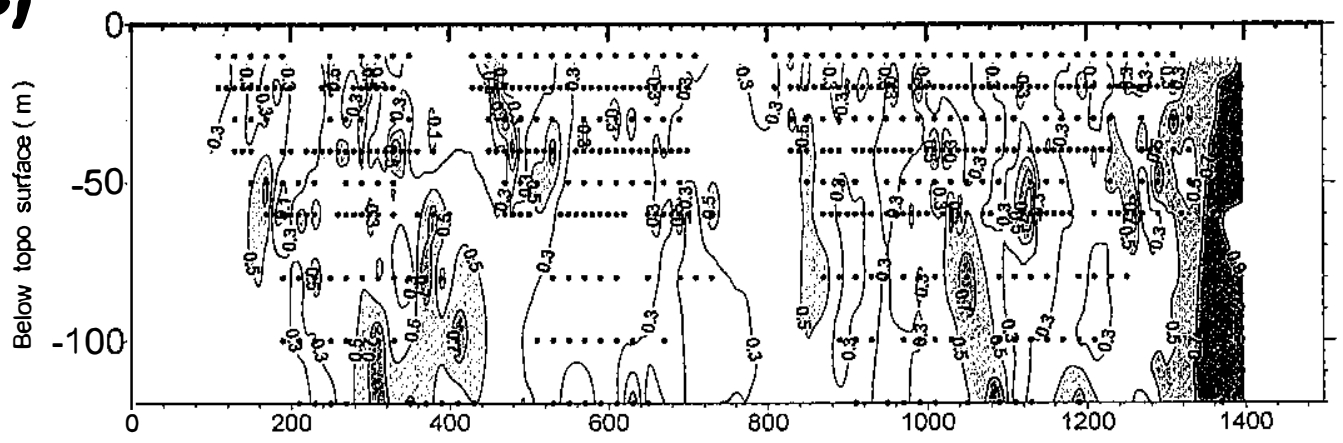

Fig. 10. The Cole-Cole parameters of the study profile. (a) The geologic section.

(b) The time constant $\mathrm{T}$ in s. (c) The exponent $\mathrm{c}$.

\subsection{Correlation with Case Histories Elsewhere in the World}

In order to correlate with the spectral IP anomalies in the southern CKS area, some time domain SIP case histories from Canada, Australia, and Finland (Seigel et al. 1997) were selected and their $\mathrm{T}$ values organized in Table 2. 
Table 2. Characteristic T values of typical SIP sources employed to correlate with this study.

\begin{tabular}{|c|c|c|c|}
\hline SIP sources worldwide & $\mathrm{T}(\mathrm{s})$ worldwide & $\begin{array}{l}\mathrm{T} \text { (s) of this } \\
\text { study }\end{array}$ & $\begin{array}{c}\text { Promising } \\
\text { gold-bearing } \\
\text { order of this } \\
\text { study }\end{array}$ \\
\hline Background (non-metallic) & $10^{-2}$ to $10^{-1}$ & less than $10^{-0.5}$ & \\
\hline $\begin{array}{l}\text { Gold deposits with } \\
\text { disseminated sulphides }\end{array}$ & $10^{-2}$ to $10^{-1}$ & $10^{-0.5}$ to $10^{0.5}$ & 4 \\
\hline $\begin{array}{l}\text { Bedded lead-zinc } \\
\text { (Miss. Valley type deposits) }\end{array}$ & $10^{-2}$ to $10^{-0}$ & $10^{-0.5}$ to $10^{0.5}$ & 2 \\
\hline Porphyry copper deposits & $10^{-2}$ to $10^{0}$ & $10^{-0.5}$ to $10^{0.5}$ & $\mathbf{1}$ \\
\hline Massive pyritic sulphides & $10^{0}$ to $10^{2}$ & $10^{-0.5}$ to $10^{0.5}$ & 3 \\
\hline Magnetite-related ultramafics & $10^{0}$ to $10^{2}$ & $10^{-0.5}$ to $10^{0.5}$ & 5 \\
\hline Pyrrhotite related deposits & $10^{1}$ to $10^{2}$ & & \\
\hline $\begin{array}{l}\text { Cultural sources (Pipe lines, } \\
\text { grounded power lines, fences, } \\
\text { etc.) }\end{array}$ & $10^{1}$ to $10^{2}$ & & \\
\hline
\end{tabular}

Based on Table 2, the SIP anomaly with T values ranging $10^{-0.5}$ to $10^{0.5} \mathrm{~s}$ in the study area is possible caused by porphyry gold/copper mineralizations, gold veins, or breccia pipes. However, in a new area, the approach should be "calibrated" over known geological conditions prior to placing reliance on its criteria in adjacent areas to be explored.

After constrainment with the adjacent ore deposits, the Sumay deposit, some $2 \mathrm{~km}$ north of the studying area, which consists of gold with disseminated pyrite without magnetite-related ultramafics, the most promising orders of gold-bearing deposits, at present stage, are as follow, (1) porphyry gold/copper mineralizations, (2) gold veins, and (3) breccia pipes. These promising orders of possible IP sources have also been indicated in the right most column of the Table 2 for clarification.

\section{SUMMARY}

The spectral time domain IP method is the most cost effective way to obtain enough SIP information routinely; together with the potential power to discriminate between different sources of IP responses, spectral time domain IP has been becoming one of the most popular and the highest resolution electrical methods. This technique has first been applied to the southern CKS area to the resolution of IP sources. Based on the Cole-Cole parameters acquired, especially $\mathrm{T}$ values (ranging $10^{-0.5}$ to $10^{0.5} \mathrm{~s}$ ), the possible concealed mineral deposits (porphyry gold/copper deposits, or breccia pipes) in the margin of the Wutanshan intrusion were discovered and located. 
Acknowledgments The authors greatly appreciate the valuable suggestions provided by Professors L. P. Tan and L. T. Tong, who painstakingly reviewed the manuscript and recommended numerous improvements. This study was financially supported in part by the Central Geological Survey of the Republic of China under grant 89EC2A380201, and in part by the National Science Council of the Republic of China under grant NSC89-2116-M-008-018.

\section{REFERENCES}

Pelton, W. H., S. H. Ward, P. G. Hallof, W. R. Sill, and P. H. Nelson, 1978: Mineral discrimination and removal of inductive coupling with multifrequency IP. Geophysics, 43, 588609.

Seigel, H. O., H. Vanhala, and S. N. Sheard, 1997: Some case histories of source discrimination using time-domain spectral IP. Geophysics, 62, 1394-1408.

Sumner, J. S., 1976: Principles of induced polarization for geophysical exploration. Elsevier Scientific Publishing Company, Amsterdam, pp 277.

Tan, L. P., 1991: The Chinkuashih gold-copper deposits, Taiwan. Soc. Economic Gelolgists News Letter, 7 , 21-24.

Tombs, J. M. C., 1981: The feasibility of making spectral IP measure-ments in the time domain. Geoexpl., 19, 91-102.

Tong, L. D., and W. S. Chen, 2000: Geophysical survey between Chinkuashih and Chinmenshan, northern Taiwan. Report of the Central Geological Survey, 89-07, pp79 (In Chinese).

Tzou, Y. H., 1979: Gravity pattern in Chilung volcano group, northern Taiwan. Bull. Inst. Geophysics, Nat. Central University, 18, 25-33. 